\title{
Retrospective observational study of salvage line ramucirumab monotherapy for patients with advanced gastric cancer
}

\author{
Sadayuki Kawai ${ }^{1 *}$, Naoki Fukuda ${ }^{2}$, Shun Yamamoto ${ }^{3}$, Seiichiro Mitani ${ }^{4}$, Katsuhiro Omae $^{5}$, Takeru Wakatsuki ${ }^{2}$, \\ Ken Kato ${ }^{3}$, Shigenori Kadowaki ${ }^{4}$, Daisuke Takahari ${ }^{2}$, Narikazu Boku ${ }^{3}$, Kei Muro ${ }^{4}$ and Nozomu Machida ${ }^{1}$
}

\begin{abstract}
Background: Ramucirumab monotherapy as a second-line treatment for advanced gastric cancer (AGC) prolongs survival compared to the best supportive care. However, in clinical practice, ramucirumab monotherapy is sometimes used as third- or later-line treatment for AGC refractory to fluoropyrimidine and taxanes. This study evaluated the efficacy and safety of salvage-line ramucirumab monotherapy for treating AGC.

Methods: The subjects of this retrospective study were advanced gastric or gastro-esophageal junction adenocarcinoma patients who received ramucirumab monotherapy after failure of 2 or more prior regimens containing fluoropyrimidine and taxanes but not ramucirumab.

Results: From June 2015 to April 2017, 51 patients were enrolled. The median progression-free survival (PFS) and overall survival (OS) were 1.8 (95\% confidence interval $[\mathrm{Cl}]=1.6-2.2)$ and $5.1(95 \% \mathrm{Cl}=4.0-6.8)$ months, respectively. The objective response and disease control rates were 2 and 17\%, respectively. Grade 3 adverse events (AEs; e.g.r anemia, fatigue, hypertension, proteinuria, intestinal bleeding) occurred in seven (13\%) patients, but no grade 4 AEs and treatment-related deaths were observed. A neutrophil-lymphocyte ratio (NLR) of $<2.5$ and previous gastrectomy were associated with better PFS.

Conclusions: Salvage-line ramucirumab monotherapy has acceptable toxicity and comparable efficacy to second-line treatment; therefore, we consider physicians might choose this therapy as a salvage-line treatment option for AGC refractory to the standard therapies.
\end{abstract}

Keywords: Stomach neoplasms, Drug therapy, Salvage therapy, Ramucirumab

\section{Background}

Gastric cancer is the third leading cause of death due to cancer worldwide [1]. Chemotherapy is the standard treatment for patients with advanced (unresectable or recurrent) gastric cancer (AGC). Although recent developments in chemotherapies for AGC have prolonged patients' survival, their prognoses remain poor. The commonly used regimen for first-

\footnotetext{
* Correspondence: sadayuki-kawai@i.shizuoka-pho.jp

'Division of Gastrointestinal Oncology, Shizuoka Cancer Center, 1007 Shimonagakubo, Nagaizumi, Sunto-gun, Shizuoka 411-8777, Japan Full list of author information is available at the end of the article
}

line treatment of AGC is combination chemotherapy, including fluoropyrimidine and platinum, which achieves a median progression-free survival (PFS) of $\sim 6$ months and a median overall survival (OS) of $\sim 1$ year [2-4].

In a randomized phase III "Ramucirumab Monotherapy for Previously Treated Advanced Gastric or Gastroesophageal Junction Adenocarcinoma" (REGARD) trial, administering ramucirumab, an anti-vascular endothelial growth factor receptor (anti-VEGFR) monoclonal antibody, as a second-line treatment prolonged OS compared to the placebo (hazard ratio $[\mathrm{HR}]=0.774 ; 95 \%$

(c) The Author(s). 2020 Open Access This article is licensed under a Creative Commons Attribution 4.0 International License, which permits use, sharing, adaptation, distribution and reproduction in any medium or format, as long as you give appropriate credit to the original author(s) and the source, provide a link to the Creative Commons licence, and indicate if changes were made. The images or other third party material in this article are included in the article's Creative Commons licence, unless indicated otherwise in a credit line to the material. If material is not included in the article's Creative Commons licence and your intended use is not permitted by statutory regulation or exceeds the permitted use, you will need to obtain permission directly from the copyright holder. To view a copy of this licence, visit http://creativecommons.org/licenses/by/4.0/. The Creative Commons Public Domain Dedication waiver (http://creativecommons.org/publicdomain/zero/1.0/) applies to the data made available in this article, unless otherwise stated in a credit line to the data. 
confidence interval $(\mathrm{CI})=0.605-0.991)$ [5]. In addition, in a "Ramucirumab plus Paclitaxel versus Placebo plus Paclitaxel for Previously Treated Advanced Gastric or Gastroesophageal Junction Adenocarcinoma" (RAINBOW) trial, combination chemotherapy, including ramucirumab and paclitaxel as a second-line treatment, prolonged OS compared to the placebo and paclitaxel regimen ( $\mathrm{HR}=0.807 ; 95 \% \mathrm{CI}=0.678-0.962)$ [6]. Therefore, ramucirumab and paclitaxel doublet therapy is currently considered a standard second-line treatment, and ramucirumab monotherapy is also considered a secondline treatment option for AGC.

In clinical practice, some patients with AGC refractory to taxanes (e.g., patients who had an early relapse or progression during or soon after taxane-containing perioperative treatment) underwent ramucirumab monotherapy as third- or later-line treatment. Recent evidence has demonstrated that a taxane-containing regimen is beneficial in a perioperative setting. Al-Batran et al. [7] showed that a combination regimen, including fluorouracil, leucovorin, oxaliplatin, and docetaxel (FLOT), for resectable gastric cancer patients in a perioperative setting prolongs OS compared to a combination regimen including epirubicin, platinum, and fluorouracil. Yoshida et al. [8] reported that S-1 and docetaxel as adjuvant therapy prolonged relapse-free survival compared to S-1 alone. For patients who have an early relapse, despite undergoing docetaxel-containing perioperative chemotherapy, second-line chemotherapy without taxane (e.g., irinotecan or nivolumab) is considered optimal because of cross-resistance between docetaxel and paclitaxel [9, 10]. In such situations, ramucirumab monotherapy would be administered as third- or later-line treatment.

There are few reports on the efficacy and safety of ramucirumab monotherapy as third- or later-line treatment. Therefore, this retrospective, observational study evaluated the efficacy and safety of ramucirumab monotherapy as third- or later-line treatment for AGC refractory or intolerant to fluoropyrimidines and taxanes.

\section{Methods}

\section{Patients}

This study is a multicenter retrospective observational study. AGC patients who underwent ramucirumab monotherapy as third- or later-line treatment between June 2015 and April 2017 at four institutions in Japan were enrolled in this study. All data were retrospectively collected from patients' medical records. The inclusion criteria were as follows: age $\geq 18$ years, histologically proven adenocarcinoma of the stomach or the gastroesophageal junction (GEJ), Eastern Cooperative Oncology Group (ECOG) performance status (PS) $\leq 2$, and disease refractory to, or intolerant of, fluoropyrimidine and taxanes. The human epidermal growth factor receptor 2 (HER2) expression status was not considered. The exclusion criteria were as follows: severe bleeding, cardiovascular events, and uncontrolled comorbidities (e.g., hypertension, heart failure, or infection). Therefore, 51 patients were enrolled.

The study was approved by the ethics committees of all participating institutions based on biomedical research guidelines specified in the Declaration of Helsinki. Since the study was retrospective, informed consent was waived. Authors uploaded the information about this study and patients' rights to the participating institutions' websites.

\section{Treatment}

All 51 patients underwent ramucirumab monotherapy at a dose of $8 \mathrm{mg} / \mathrm{kg}$ biweekly. Treatment was stopped in cases of disease progression, unacceptable toxicity, or patient refusal. The dose was reduced or treatment delayed at each physician's discretion based on a specific patient's condition and the severity of toxicity. The relative dose intensity (RDI) was calculated as follows:

RDI $=($ Total actually administered dose $/$ Planned dose during treatment $) \times 100$

\section{Evaluation and statistical analysis}

The following data was collected from each patient: age, sex, ECOG PS, primary tumor location, tumor histology, HER2 status, metastatic sites, prior treatment, time that first-line treatment began, comorbidity, concomitant medication, and laboratory data at the start of ramucirumab monotherapy. The neutrophil-lymphocyte ratio (NLR) was calculated as follows:

$\mathrm{NLR}=$ Absolute neutrophil count/Absolute lymphocyte count

The platelet-lymphocyte ratio (PLR) was defined as follows:

PLR $=$ Absolute platelet count/Absolute lymphocyte count

The cutoff values for the NLR and PLR were determined as 2.5 and 250, respectively, as described previously [11-13].

OS was calculated from the date of starting ramucirumab monotherapy until death due to any cause and censored at the last contact with surviving patients. PFS was calculated from the date of starting ramucirumab monotherapy until disease progression based on radiological images or clinical judgment and censored at the last contact with surviving patients without disease progression. Tumor responses were evaluated in patients with measurable lesions according to the Response Evaluation Criteria in Solid Tumors (RECIST) ver. 1.1 [14]. Toxicity was assessed according to the Common Terminology Criteria for Adverse Events (CTCAE) ver. 4.0. The PFS and OS were estimated using the Kaplan-Meier method. 
The association between each patient's background factors with the PFS or OS was estimated by univariate analysis using the log-rank test, and statistically significant background factors in univariate analysis were included in multivariate analysis using the Cox regression model. For categorical data, we again performed univariate analysis using Fisher's exact test and multivariate analysis using the logistic regression model. Because our study was a retrospective exploratory analysis, sample size was not estimated a priori. All statistical analyses were conducted using EZR statistical software ver. 1.30 [15], and all statistical tests were two sided. $P<0.05$ was considered statistically significant.

\section{Results}

\section{Patients' characteristics}

Table 1 shows the backgrounds of the 51 patients enrolled in this study. Briefly, the patients' median age was 67 years (range $=39-84$ years), and $41(80 \%)$ patients were male. Of the 51 patients, $43(84 \%)$ had ECOG PS = 0 or $1.35(69 \%)$ were histologically diagnosed with intestinal-type adenocarcinoma, 17 (33\%) were HER2 positive, and 29 (57\%) had $\geq 2$ metastatic sites.

Forty-four (86\%) patients underwent $\geq 3$ prior chemotherapies, 44 (86\%) received S-1 as fluoropyrimidine, 39 (76\%) were administered cisplatin as platinum in firstline treatment, 46 (90\%) were administered paclitaxel as taxane in second-line treatment, and 11 (21\%) were administered immune checkpoint inhibitors (ICIs). The median time from starting first-line treatment was 22.2 months (range $=8.4-52.1$ months). In addition, 5 (10\%) patients were administered antiplatelet or anticoagulant drugs because of a past history of ischemic heart disease or stroke, $11(21 \%)$ were administered nonsteroidal antiinflammatory drugs (NSAIDs) for cancer pain, and 16 (31\%) had a history of hypertension.

\section{Treatments}

The median number of ramucirumab monotherapy administrations in each patient was 4 cycles (range $=1-31$ cycles), with a total of 281 cycles in all 51 patients. No patient required a dose reduction in subsequent courses. However, administration of ramucirumab monotherapy was delayed in $12(23 \%)$ patients (total 18 cycles) because of patients' wishes, a holiday, or minor adverse events (AEs) such as grade 2 hypertension, grade 2 proteinuria, and grade 1 fever. The median RDI of ramucirumab monotherapy in all patients was $100 \%$ (range $=76-100 \%$ ). Of the 51 patients, ramucirumab monotherapy was discontinued in 47 (92\%) patients because of disease progression (44 patients, $86 \%$ ) and AEs (3 patients, $6 \%$; grade 3 small intestinal hemorrhage in 1 patient and grade 3 proteinuria in 2 patients). As subsequent therapy, best supportive care was performed in 29 (57\%) patients, and chemotherapies were administered to 18 (35\%) patients, including a fluoropyrimidine rechallenge in 7 (14\%), irinotecan in 5 (10\%), and ICIs in $3(6 \%)$ patients.

\section{Efficacy}

Of the $42(82 \%)$ patients with measurable lesions, we were unable to evaluate the tumor response in $8(16 \%)$ patients because of disease progression, clinically judged, in 5 patients, discontinuation due to AEs in 2, and treatment before evaluation by imaging in 1 . In addition, 1 patient achieved partial response, while 6 patients showed stable disease, resulting in a response rate (RR) of $2 \%$ and a disease control rate (DCR) of $17 \%$. For proportions of change in target lesions at the best response, compared to the baseline, please refer to the waterfall plot in Fig. 1. After a median follow-up period of 8.9 months, the median PFS was 1.8 months $(95 \% \mathrm{CI}=1.6-$ 2.2 ) and the median OS was 5.1 months $(95 \% \mathrm{CI}=4.0$ 6.8) (Fig. 2).

\section{Prognostic factors}

Patients with NLR $<2.5$ and those with previous gastrectomy had longer PFS (Table 2). Although no background factors were identified as significant prognostic factors for OS (Table 3), NLR $<2.5$ was associated with longer OS. Patients with NLR $<2.5$ also tended to have a high DCR (4 of $11,36 \%$ ) compared to NLR $\geq 2.5$ (3 of $23,13 \%)$. We also investigated the relationship between prior therapies and the efficacy of ramucirumab. However, multivariate analysis did not showed significant difference between them (data not shown).

\section{Safety}

Table 4 lists the hematological and non-hematological AEs associated with ramucirumab monotherapy. Overall, 38 of 51 (74\%) patients had at least one treatmentrelated AE, while 7 (13\%) had grade 3 AEs, including anemia ( 2 patients, $4 \%$ ), fatigue (1 patient, $2 \%$ ), hypertension (2 patients, $4 \%$ ), proteinuria (2 patients, $4 \%$ ), and bleeding (1 patient, $2 \%$ ). We did not observe grade 4 AEs and treatment-related death. Univariate analysis showed no significant relationship between each AE and the patient's background (data not shown).

\section{Discussion}

As second-line treatment for AGC, the REGARD trial showed a median PFS of 2.1 months and a median OS of 5.2 months [5]. A Japanese trial on ramucirumab monotherapy as second-line treatment showed a median PFS of 1.6 months and a median OS of 7.3 months [16]. This favorable OS, despite a PFS similar to that in this study, might be obtained by patient selection and subsequent treatments. We believe that the efficacy of ramucirumab monotherapy as third- or later-line treatment, as shown 
Table 1 Patients' characteristics in this study $(n=51)$

\begin{tabular}{|c|c|c|c|}
\hline & & Number & $\%$ \\
\hline Age & Median (range) & 67 (39-84) & \\
\hline \multirow[t]{2}{*}{ Sex } & Male & 41 & 80 \\
\hline & Female & 10 & 20 \\
\hline \multirow[t]{3}{*}{ ECOG PS } & 0 & 4 & 8 \\
\hline & 1 & 39 & 76 \\
\hline & 2 & 8 & 15 \\
\hline \multirow[t]{2}{*}{ Location of primary tumor } & Stomach & 43 & 84 \\
\hline & GEJ & 8 & 16 \\
\hline \multirow[t]{2}{*}{ Histology } & intestinal & 35 & 69 \\
\hline & diffuse & 16 & 31 \\
\hline HER2 overexpression & $(+)$ & 17 & 33 \\
\hline Previous gastrectomy & $(+)$ & 24 & 47 \\
\hline \multirow[t]{2}{*}{ Number of metastatic sites } & $0-1$ & 22 & 43 \\
\hline & 2 or more & 29 & 57 \\
\hline \multirow[t]{4}{*}{ Metastatic sites } & Lymph nodes & 9 & 18 \\
\hline & Liver & 33 & 65 \\
\hline & Lung & 11 & 22 \\
\hline & Peritoneum & 23 & 45 \\
\hline Ascites & $(+)$ & 21 & 41 \\
\hline $\begin{array}{l}\text { Time from initiation of 1st } \\
\text { line therapy }\end{array}$ & $\geq 2$ years & 22 & 43 \\
\hline \multirow[t]{4}{*}{ Number of prior therapies } & 2 & 7 & 14 \\
\hline & 3 & 25 & 49 \\
\hline & 4 & 12 & 24 \\
\hline & 5 & 7 & 14 \\
\hline \multirow[t]{11}{*}{ Agents of prior therapies } & S-1 & 43 & 84 \\
\hline & Capecitabine & 14 & 27 \\
\hline & $5-\mathrm{FU}$ & 6 & 12 \\
\hline & Cisplatin & 39 & 76 \\
\hline & Oxaliplatin & 17 & 33 \\
\hline & Paclitaxel & 46 & 90 \\
\hline & Docetaxel & 9 & 18 \\
\hline & Irinotecan & 41 & 80 \\
\hline & Trastuzumab & 15 & 29 \\
\hline & $\mathrm{ICl}$ & 11 & 21 \\
\hline & Others & 12 & 23 \\
\hline $\begin{array}{l}\text { Concomitant use of antiplatelet } \\
\text { or anticoagulation therapy }\end{array}$ & $(+)$ & 5 & 10 \\
\hline Concomitant use of NSAIDs & $(+)$ & 11 & 22 \\
\hline History of hypertension & $(+)$ & 16 & 31 \\
\hline Neutrophil-lymphocyte ratio & $<2.5$ & 16 & 31 \\
\hline Platelet-lymphocyte ratio & $<250$ & 29 & 57 \\
\hline ALP & $<W N L$ & 22 & 43 \\
\hline CRP & $<W N L$ & 15 & 29 \\
\hline LDH & $<W N L$ & 19 & 57 \\
\hline
\end{tabular}

Abbreviations: ECOG PS Eastern Cooperative Oncology Group performance status, HER2 human epidermal growth factor receptor 2, GEJ gastroesophageal junction, ICI immune checkpoint inhibitor, NSAIDs nonsteroidal anti-inflammatory drugs, ALP alkaline phosphatase, CRP C-reactive protein, $L D H$ lactate dehydrogenase, $W N L$ within normal limits 


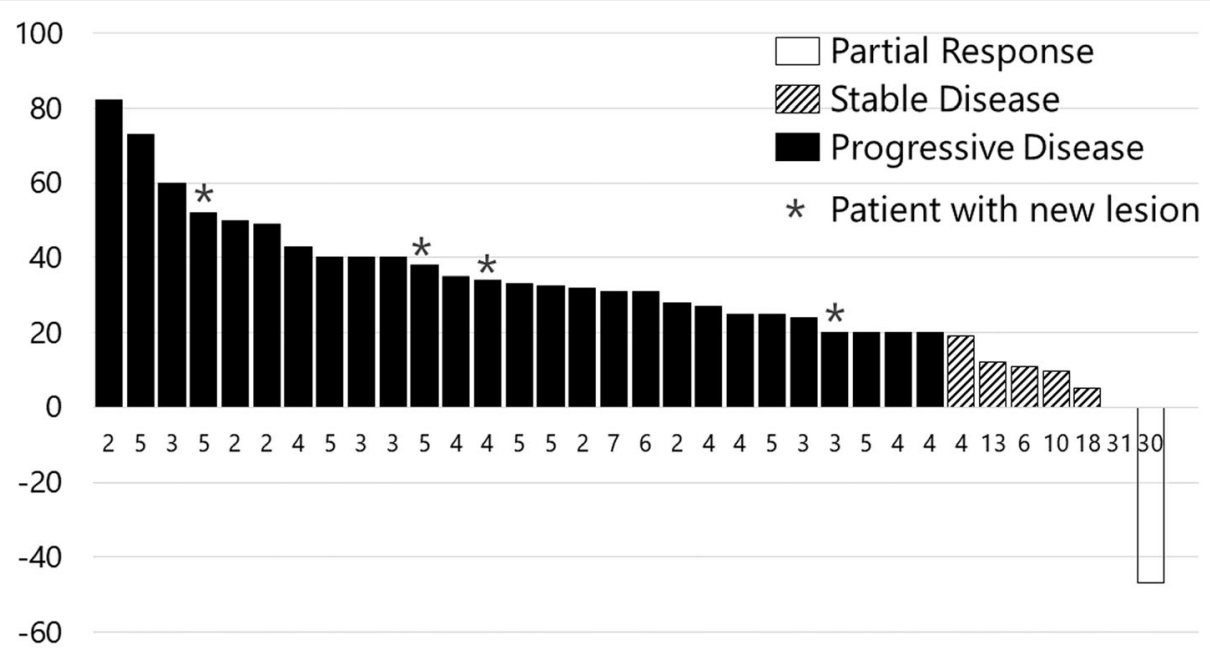

(\%)

Fig. 1 Waterfall plot of tumor response for evaluable patients $(n=34)$. The numbers beside each bar are ramucirumab administration cycles. *Patients with a new lesion at the first evaluation

in this study, is comparable to previous studies that reported ramucirumab monotherapy as second-line treatment.

Paulson et al. [17] reported retrospective observational data on ramucirumab monotherapy for AGC patients in the United States. They studied 115 patients who underwent ramucirumab monotherapy, $38.3 \%$ of whom underwent ramucirumab monotherapy as third- or later-line treatment. The authors reported that the median duration of therapy was 1.87 months; the median OS and RR were not reported. Murahashi et al. [18] retrospectively analyzed the efficacy and safety of ramucirumab monotherapy as second- or later-line treatment at a single institution. The authors reported that 15 of their 19 patients underwent ramucirumab monotherapy as third- or later-line treatment. Overall, the median OS, median PFS, RR, and grade $3 \mathrm{AE}$ incidence were 12.9 months, 2.1 months, 7.7, and $10 \%$, respectively. Our results were comparable to these reports, suggesting prolonged survival after salvageline ramucirumab monotherapy for AGC.

The NLR is reportedly a poor prognostic factor in several cancers, such as colon, breast, pancreatic, and gastric cancer [19-22], in a metastatic or an adjuvant setting. The NLR is an inflammation marker; a high NLR reflects
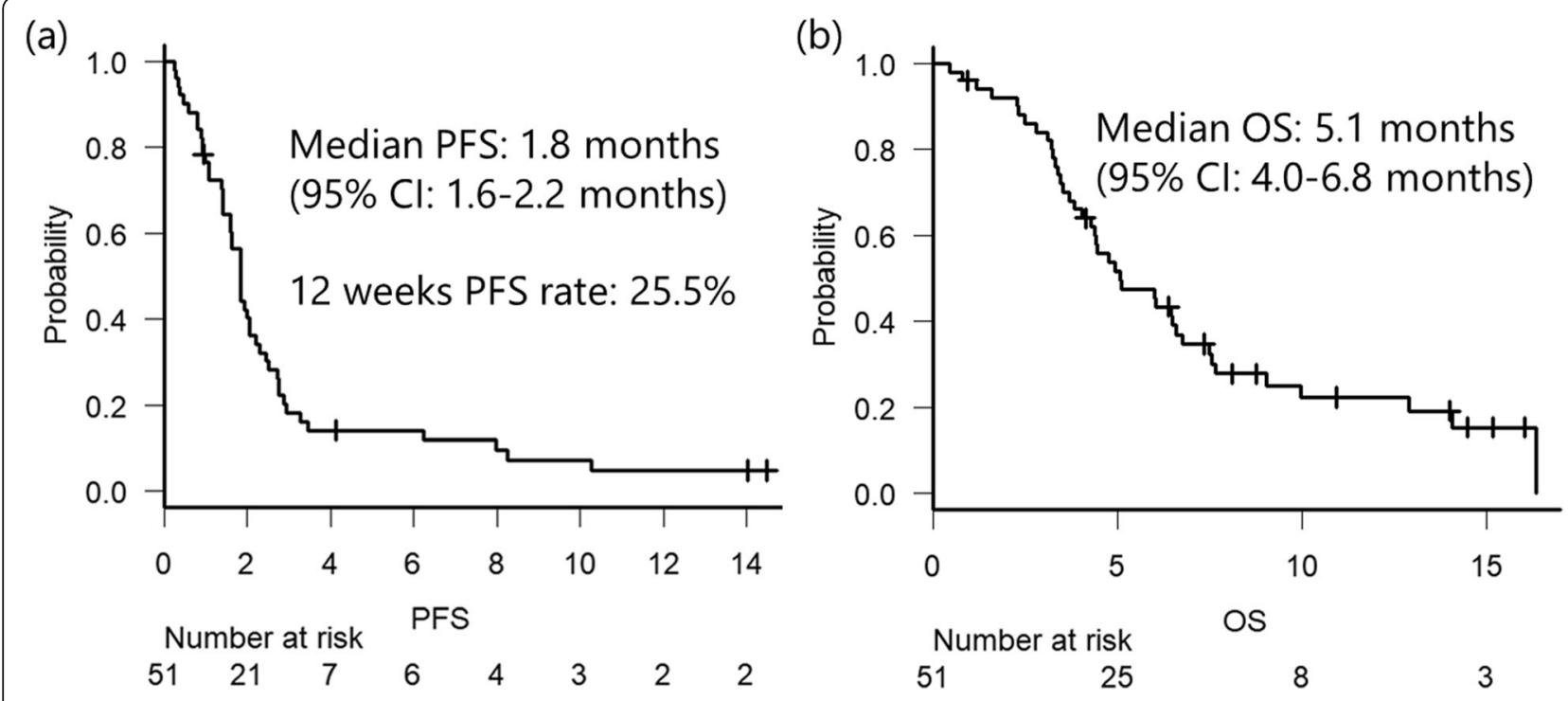

Fig. 2 Kaplan-Meier curves of PFS (a) and OS (b). PFS, progression-free survival; OS, overall survival 
Table 2 Exploratory analysis of prognostic factors for PFS

\begin{tabular}{|c|c|c|c|c|c|}
\hline \multirow[t]{2}{*}{ Covariates } & & \multicolumn{2}{|c|}{ Univariate analysis } & \multicolumn{2}{|c|}{ Multivariate analysis } \\
\hline & & $\mathrm{HR}(95 \% \mathrm{Cl})$ & $P$ & $\mathrm{HR}(95 \% \mathrm{Cl})$ & $P$ \\
\hline Number of prior therapies & $\geq 4$ & $1.37(0.73-2.56)$ & 0.324 & & \\
\hline Sex & male & $0.65(0.31-1.37)$ & 0.261 & & \\
\hline Age & $>66$ & $0.97(0.53-1.76)$ & 0.931 & & \\
\hline ECOG PS & 2 & $1.57(0.72-3.41)$ & 0.251 & & \\
\hline Location of primary tumor & Stomach & $0.59(0.35-1.37)$ & 0.222 & & \\
\hline Histology & diffuse & $0.85(0.44-1.63)$ & 0.636 & & \\
\hline HER2 overexpression & $(+)$ & $1.52(0.80-2.87)$ & 0.192 & & \\
\hline $\begin{array}{l}\text { Concomitant use of NSAIDs / antiplatelets } \\
\text { / anticoagulation therapy }\end{array}$ & $(+)$ & $1.12(0.60-2.11)$ & 0.709 & & \\
\hline History of hypertension & $(+)$ & $0.53(0.27-1.04)$ & 0.066 & & \\
\hline Number of metastatic sites & $\geq 2$ & $1.51(0.83-2.75)$ & 0.17 & & \\
\hline Ascites & $(+)$ & $1.78(0.97-3.26)$ & 0.061 & & \\
\hline Peritoneal metastasis & $(+)$ & $1.32(0.74-2.37)$ & 0.339 & & \\
\hline Previous gastrectomy & $(+)$ & $0.48(0.26-0.89)$ & 0.019 & $0.50(0.27-0.94)$ & 0.031 \\
\hline Time from initiation of 1st line therapy & $\geq 2$ years & $0.53(0.29-0.98)$ & 0.043 & $0.66(0.35-1.25)$ & 0.208 \\
\hline Prior history of $\mathrm{ICl}$ & $(+)$ & $1.03(0.52-2.06)$ & 0.92 & & \\
\hline ALP & $\geq W N L$ & $1.08(0.59-1.98)$ & 0.797 & & \\
\hline CRP & $\geq W N L$ & $1.34(0.71-2.51)$ & 0.359 & & \\
\hline LDH & $\geq \mathrm{WNL}$ & $1.42(0.74-2.74)$ & 0.285 & & \\
\hline NLR & $<2.5$ & $0.35(0.16-0.74)$ & 0.002 & $0.38(0.17-0.87)$ & 0.017 \\
\hline PLR & $<250$ & $0.58(0.32-0.97)$ & 0.033 & $0.83(0.44-1.56)$ & 0.413 \\
\hline
\end{tabular}

Abbreviations: PFS progression-free survival, HR hazard ratio, Cl confidence interval, ECOG PS Eastern Cooperative Oncology Group performance status, HER2 human epidermal growth factor receptor 2, NSAIDs nonsteroidal anti-inflammatory drugs, ICI immune checkpoint inhibitor, ALP alkaline phosphatase, CRP Creactive protein, $L D H$ lactate dehydrogenase, $W N L$ within normal limits

enhanced systemic inflammation and is associated with reduced tumor-specific immunity, such as decreased tumor-infiltrating lymphocytes in a tumor [23]. Neutrophilia inhibits the cytolytic activity of immune cells [24] and increases the production of factors that promote tumor growth, such as VEGF and hepatocyte growth factor [25]. Lymphocytopenia is often observed in patients with advanced disease, indicating a state of immunosuppression [26]. From a pooled analysis of REGARD and RAINBOW trials, Fuchs et al. [27] reported that 12 clinical and laboratory factors, including a high neutrophil and low lymphocyte count, at the start of ramucirumab monotherapy are negative prognostic factors for OS. From Korean retrospective cohort data of ramucirumab mono- or combination therapy, Jung et al. [28] reported that the NLR and albumin are independent prognostic factors for the PFS and OS. Our results also supported these findings.

Although studies have evaluated several predictive biomarkers of antiangiogenic therapy, no reproducible biomarkers, including soluble VEGF-C, VEGF-D, VEGFR1, and VEGFR3, have been identified in the REGARD trial [29]. Some studies have suggested the NLR's predictive value. Cho et al. [30] reported that AGC patients with low NLRs have higher DCRs for cytotoxic chemotherapy compared to patients with high NLRs. Similarly, the association between the NLR and the tumor response of chemotherapy has been reported in several neoplasms, such as colon, head and neck, and lung cancer [20, 31, 32]. The immunological response caused by chemotherapy could be a reason for these findings. Compared to patients with high NLRs, patients with low NLRs are likely to have the inflammatory reaction environment mediated by lymphocytes [30]. Ogata et al. [33] and Bagley et al. [34] reported that the NLR might predict the tumor response of nivolumab in gastric cancer and non-small cell lung cancer, respectively. Tada et al. [35] reported that ramucirumab suppresses tumor infiltration of effector regulatory T-cells (eTreg) and decreases programmed cell death protein 1 (PD-1) expression by CD8+ T-cells, subsequently enhancing antitumor immunity. Therefore, the NLR might also predict the ramucirumab-induced immunological antitumor effect.

In third-line treatment, the patients' performance status is generally worse than second-line treatment. In the REGARD and Japanese prospective phase II trials, 28 and $66 \%$ of patients had ECOG PS $=0$, respectively [5, 16 , compared to $8 \%$ in our study; in addition, $15 \%$ of 
Table 3 Exploratory analysis of prognostic factors for OS

\begin{tabular}{|c|c|c|c|c|c|}
\hline \multirow[t]{2}{*}{ Covariates } & & \multicolumn{2}{|c|}{ Univariate analysis } & \multicolumn{2}{|c|}{ Multivariate analysis } \\
\hline & & $\mathrm{HR}(95 \% \mathrm{Cl})$ & $P$ & $\mathrm{HR}(95 \% \mathrm{Cl})$ & $P$ \\
\hline Number of prior therapies & $\geq 4$ & $1.56(0.81-2.99)$ & 0.176 & & \\
\hline Sex & Male & $0.66(0.30-1.45)$ & 0.304 & & \\
\hline age & $>66$ & $0.87(0.46-1.64)$ & 0.671 & & \\
\hline ECOG PS & 2 & $1.61(0.71-3.68)$ & 0.252 & & \\
\hline Location of primary tumor & Stomach & $1.12(0.46-2.70)$ & 0.795 & & \\
\hline Histology & diffuse & $1.09(0.55-2.16)$ & 0.801 & & \\
\hline HER2 overexpression & $(+)$ & $1.59(0.81-3.12)$ & 0.171 & & \\
\hline $\begin{array}{l}\text { Concomitant use of NSAIDs/antiplatelets } \\
\text { /anticoagulation therapy }\end{array}$ & $(+)$ & $1.60(0.80-3.18)$ & 0.18 & & \\
\hline History of hypertension & $(+)$ & $0.71(0.35-1.47)$ & 0.371 & & \\
\hline Number of metastatic sites & $\geq 2$ & $1.86(0.97-3.59)$ & 0.061 & & \\
\hline Ascites & $(+)$ & $1.88(0.99-3.56)$ & 0.05 & & \\
\hline Peritoneal metastasis & $(+)$ & $0.79(0.41-1.49)$ & 0.468 & & \\
\hline Previous gastrectomy & $(+)$ & $0.71(0.37-1.35)$ & 0.297 & & \\
\hline Time from initiation of 1st line therapy & $\geq 2$ years & $0.67(0.35-1.31)$ & 0.249 & & \\
\hline Prior history of $\mathrm{ICl}$ & $(+)$ & $1.45(0.68-3.10)$ & 0.329 & & \\
\hline ALP & $\geq W N L$ & $1.28(0.67-2.46)$ & 0.444 & & \\
\hline CRP & $\geq W N L$ & $2.18(1.02-4.61)$ & 0.041 & $1.72(0.76-3.89)$ & 0.187 \\
\hline LDH & $\geq W N L$ & $2.02(1.04-3.91)$ & 0.037 & $1.66(0.74-3.70)$ & 0.149 \\
\hline NLR & $<2.5$ & $0.44(0.20-0.93)$ & 0.033 & $0.56(0.28-1.12)$ & 0.089 \\
\hline PLR & $<250$ & $0.53(0.28-1.01)$ & 0.052 & & \\
\hline
\end{tabular}

Abbreviations: OS overall survival, HR hazard ratio, Cl confidence interval, ECOG PS Eastern Cooperative Oncology Group performance status, HER2 human epidermal growth factor receptor 2, NSAIDs nonsteroidal anti-inflammatory drugs, ICl immune checkpoint inhibitor, ALP alkaline phosphatase, CRP C-reactive protein, $L D H$ lactate dehydrogenase, WNL within normal limits

Table 4 Hematological and non-hematological AEs associated with ramucirumab treatment

\begin{tabular}{lll}
\hline & Any grade (\%) & Grade $\geq 3(\%)$ \\
\hline Any adverse events & $38(74 \%)$ & $7(13 \%)$ \\
Leukopenia & $4(8 \%)$ & 0 \\
Neutropenia & $9(18 \%)$ & 0 \\
Anemia & $18(35 \%)$ & $2(4 \%)$ \\
Thrombocytopenia & $4(8 \%)$ & 0 \\
Fatigue & $19(37 \%)$ & $1(2 \%)$ \\
Anorexia & $19(37 \%)$ & $1(2 \%)$ \\
Hyponatremia & $1(2 \%)$ & $1(2 \%)$ \\
Hypertension & $18(35 \%)$ & $2(4 \%)$ \\
Proteinuria & $15(29 \%)$ & $2(4 \%)$ \\
Thrombocytopenic events & $1(2 \%)$ & 0 \\
Bleeding & $5(10 \%)$ & $1(2 \%)$ \\
Gastrointestinal perforation & 0 & 0
\end{tabular}

Abbreviations: $A E$ adverse event the patients had ECOG PS $=2$. In the REGARD and Japanese prospective phase II prospective trials, all AEs (any grade) occurred in 94 and $97 \%$ of patients ( $74 \%$ in our study), respectively, while AEs of $\geq$ grade 3 occurred in 57 and $25 \%$ of patients ( $13 \%$ in our study), respectively. These findings suggest that ramucirumab monotherapy is also feasible as salvage-line treatment.

This study had a few limitations. It was retrospective in nature, had a small sample size, and had selection bias. The median duration from the start of first-line treatment to the start of ramucirumab monotherapy was 21.9 months, which was long compared to the average of OS of AGC patients, suggesting that we selected patients with slowly growing cancers or cancers highly responsive to prior chemotherapy. However, because we analyzed multicenter data, our findings seem generalized to patients in clinical practice. Secondly, we could not assess patient's quality of life (QOL). QOL is one of the most important outcomes for the patients in salvage-line treatments. In phase III REGARD trial, ramucirumab monotherapy demonstrated the better QOL compared with best supportive care in second-line. In our study, toxicities of salvage-line ramucirumab were comparable to the second-line setting, 
and actually, $93 \%$ of patients could continue the treatment until disease progression. Therefore, we speculated salvage-line ramucirumab might have similar effect for QOL, however, further investigation is needed.

\section{Conclusions}

Ramucirumab monotherapy demonstrates acceptable efficacy and feasibility as third- or later-line treatment for AGC. We consider physicians might choose this therapy as a salvage-line treatment option for AGC refractory to the standard therapies.

\begin{abstract}
Abbreviations
AGC: Advanced gastric cancer; PFS: Progression-free survival; OS: Overall survival; Cl: Confidence interval; AE: Adverse event; NLR: Neutrophillymphocyte ratio; VEGF: Vascular endothelial growth factor; VEGFR: Vascular endothelial growth factor receptor; HR: Hazard ratio; GEJ: Gastroesophageal junction; ECOG: Eastern Cooperative Oncology Group; PS: Performance status; HER2: Human epidermal growth factor receptor 2; RDI: Relative dose intensity; PLR: Platelet-lymphocyte ratio; RECIST: Response Evaluation Criteria in Solid Tumors; CTCAE: Common Terminology Criteria for Adverse Events; NSAIDs: Nonsteroidal anti-inflammatory drugs; ICls: Immune checkpoint inhibitors; RR: Response rate; DCR: Disease control rate; PD-1: Programmed cell death protein 1; QOL: Quality of life; ALP: Alkaline phosphatase; CRP: Creactive protein; $\mathrm{LDH}$ : Lactate dehydrogenase; WNL: Within normal limits
\end{abstract}

\section{Acknowledgments}

Not applicable.

\section{Authors' contributions}

Conceptualization and study design: SK, NM, KO; Writing an original draft: SK; Project administration: NM; Review and editing: NM, SM, SK, DT, NB, KK, KO; Formal analysis: KO; Supervision: NM, KM, NB, DT, SK, TW, KK; Investigation of data: SK, NF, SY, SM, TW, KK; and All authors read and approved the final manuscript.

\section{Funding}

None.

\section{Availability of data and materials}

The datasets used and/or analyzed during the current study are available from the corresponding author on reasonable request.

\section{Ethics approval and consent to participate}

The study was approved by the ethics committees of all participating institutions based on biomedical research guidelines specified in the Declaration of Helsinki. Since the study was retrospective, informed consent was waived. Authors uploaded the information about this study and patients' rights to the participating institutions' websites. Ethics committees include Ethics Committee of Shizuoka Cancer Center (approval number: T2840-28-3-3), Ethics Review Board of National Cancer Center Hospital (approval number: 2016-363), Aichi Cancer Center Institutional Review Board (approval number: 2016-1-256), and Institutional Review Board of The cancer Institute Hospital of Japanese Foundation for Cancer Research (approval number: 2016-1150). These approvals included all administrative permissions necessary to access and use the study administrative data.

\section{Consent for publication}

Not applicable. This is just the same as described above

\section{Competing interests}

The authors declare that they have no competing interests.

\section{Author details}

'Division of Gastrointestinal Oncology, Shizuoka Cancer Center, 1007 Shimonagakubo, Nagaizumi, Sunto-gun, Shizuoka 411-8777, Japan. ${ }^{2}$ Department of Gastroenterology, Cancer Institute Hospital of Japanese Foundation For Cancer Research, 3-8-31, Ariake, Koto, Tokyo 135-8550, Japan.
${ }^{3}$ Division of Gastrointestinal Medical Oncology, National Cancer Center Hospital, 5-1-1 Tsukiji, Chuo-ku, Tokyo 104-0045, Japan. ${ }^{4}$ Department of Clinical Oncology, Aichi Cancer Center Hospital, 1-1 Kanokoden, Chikusa-ku, Nagoya 464-8681, Japan. ${ }^{5}$ Clinical Research Center, Shizuoka Cancer Center, 1007 Shimonagakubo, Nagaizumi, Sunto-gun, Shizuoka 411-8777, Japan.

Received: 1 November 2019 Accepted: 14 April 2020

Published online: 21 April 2020

\section{References}

1. Siegel RL, Miller KD, Jemal A. Cancer statistics, 2017. CA Cancer J Clin. 2017; 67:7-30.

2. Koizumi W, Narahara H, Hara T, Takagane A, Akiya T, Takagi M, et al. S-1 plus cisplatin versus S-1 alone for first-line treatment of advanced gastric cancer (SPIRITS trial): a phase III trial. Lancet Oncol. 2017;9:215-21.

3. Boku N, Yamamoto S, Fukuda H, Shirao K, Doi T, Sawaki A, et al. Fluorouracil versus combination of irinotecan plus cisplatin versus $\mathrm{S}-1$ in metastatic gastric cancer: a randomized phase 3 study. Lancet Oncol. 2009;10:1063-9.

4. Kang YK, Kang WK, Shin DB, Chen J, Xiong J, Wang J, et al. Capecitabine/ cisplatin versus 5 -fluorouracil/cisplatin as first-line therapy in patients with advanced gastric cancer: a randomised phase III noninferiority trial. Ann Oncol. 2009;20:666-73.

5. Fuchs CS, Tomasek J, Yong CJ, Dumitru F, Passalacqua R, Goswami C, et al. Ramucirumab monotherapy for previously treated advanced gastric or gastro-oesophageal junction adenocarcinoma (REGARD): an international, randomised, multicentre, placebo-controlled, phase 3 trial. Lancet. 2014;383: $31-9$

6. Wilke H, Muro K, Van Cutsem E, Oh SC, Bodoky G, Shimada Y, et al. Ramucirumab plus paclitaxel versus placebo plus paclitaxel in patients with previously treated advanced gastric or gastro-oesophageal junction adenocarcinoma (RAINBOW): a double-blind, randomised phase 3 trial. Lancet Oncol. 2014;15:1224-35.

7. Al-Batran SE, Homann N, Pauligk C, Goetze TO, Meiler J, Kasper S, et al. Perioperative chemotherapy with fluorouracil plus leucovorin, oxaliplatin, and docetaxel versus fluorouracil or capecitabine plus cisplatin and epirubicin for locally advanced, resectable gastric or gastro-oesophageal junction adenocarcinoma (FLOT4): a randomised, phase 2/3 trial. Lancet. 2019;393:1948-57.

8. Yoshida K, Kodera Y, Kochi M, Ichikawa W, Kakeji Y, Sano T, et al. Addition of Docetaxel to Oral Fluoropyrimidine improves efficacy in patients with stage III gastric Cancer: interim analysis of JACCRO GC-07, a randomized controlled trial. J Clin Oncol. 2019;37:1296-304.

9. lizumi S, Takashima A, Narita Y, Tajika M, Muro K, Kawai S, et al. Efficacy and safety of taxane monotherapy in advanced gastric cancer refractory to triplet chemotherapy with docetaxel, cisplatin, and S-1: a multicenter retrospective study. Cancer Chemother Pharmacol. 2017:80:575-82.

10. Shimura T, Kitagawa M, Yamada T, Yoshida M, Ebi M, Hirata Y, et al. The impact of cross-resistance between paclitaxel and docetaxel for metastatic gastric cancer. Onkologie. 2012;35:176-83.

11. Tanaka H, Muguruma K, Toyokawa T, Kubo N, Ohira M, Hirakawa K. Differential impact of the neutrophil-lymphocyte ratio on the survival of patients with stage IV gastric cancer. Dig Surg. 2014;31:327-33. https://doi. org/10.1159/000369278.

12. Yamanaka T, Matsumoto S, Teramukai S, Ishiwata R, Nagai Y, Fukushima M. The baseline ratio of neutrophils to lymphocytes is associated with patient prognosis in advanced gastric cancer. Oncology. 2007;73:215-20.

13. Cannon NA, Meyer J, lyengar P, Ahn C, Westover KD, Choy H, et al. Neutrophil-lymphocyte and platelet-lymphocyte ratios as prognostic factors after stereotactic radiation therapy for early-stage non-small-cell lung cancer. J Thorac Oncol. 2015;10:280-5.

14. Eisenhauer EA, Therasse P, Bogaerts J, Schwartz LH, Sargent D, Ford R, et al. New response evaluation criteria in solid tumours: revised RECIST guideline (version 1.1). Eur J Cancer. 2009:45:228-47.

15. Kanda Y. Investigation of the freely available easy-to-use software 'EZR' for medical statistics. Bone Marrow Transplant. 2013:48:452-8.

16. Yamaguchi K, Fujitani K, Nagashima F, Omuro Y, Machida N, Nishina T, et al. Ramucirumab for the treatment of metastatic gastric or gastroesophageal junction adenocarcinoma following disease progression on first-line platinum- or fluoropyrimidine-containing combination therapy in Japanese patients: a phase 2, open-label study. Gastric Cancer. 2018;21:1041-9. 
17. Paulson AS, Hess LM, Liepa AM, Cui ZL, Aguilar KM, Clark J, et al. Ramucirumab for the treatment of patients with gastric or gastroesophageal junction cancer in community oncology practices. Gastric Cancer. 2018:21:831-44.

18. Murahashi S, Takahari D, Wakatsuki T, Fukuda N, Ichimura T, Ogura M, et al. A retrospective analysis of ramucirumab monotherapy in previously treated Japanese patients with advanced or metastatic gastric adenocarcinoma. Int J Clin Oncol. 2018;23:92-7.

19. Dell'Aquila E, Cremolini C, Zeppola T, Lonardi S, Bergamo F, Masi G, et al. Prognostic and predictive role of neutrophil/lymphocytes ratio in metastatic colorectal cancer: a retrospective analysis of the TRIBE study by GONO. Ann Oncol. 2018;29:924-30.

20. Al Murri AM, Wilson C, Lannigan A, Doughty JC, Angerson WJ, McArdle CS, et al. Evaluation of the relationship between the systemic inflammatory response and cancer-specific survival in patients with primary operable breast cancer. Br J Cancer. 2017;96:891-5.

21. Cheng $H$, Long $F$, Jaiswar M, Yang L, Wang C, Zhou Z. Prognostic role of the neutrophil-to-lymphocyte ratio in pancreatic cancer: a meta-analysis. Sci Rep. 2015:5:11026.

22. Lee S, Oh SY, Kim SH, Lee JH, Kim MC, Kim KH, et al. Prognostic significance of neutrophil lymphocyte ratio and platelet lymphocyte ratio in advanced gastric cancer patients treated with FOLFOX chemotherapy. BMC Cancer. 2013;13:350

23. Coussens LM, Werb Z. Inflammation and cancer. Nature. 2002;420:860-7.

24. Petrie HT, Klassen LW, Kay HD. Inhibition of human cytotoxic T lymphocyte activity in vitro by autologous peripheral blood granulocytes. J Immunol. 1985;134:230-4

25. McCourt M, Wang JH, Sookhai S, Redmond HP. Proinflammatory mediators stimulate neutrophil-directed angiogenesis. Arch Surg. 1999;134:1325-31.

26. Chua W, Charles KA, Baracos VE, Clarke SJ. Neutrophil/lymphocyte ratio predicts chemotherapy outcomes in patients with advanced colorectal cancer. Br J Cancer. 2011;104:1288-95.

27. Fuchs CS, Muro K, Tomasek J, Van Cutsem E, Cho JY, Oh SC, et al. Prognostic factor analysis of overall survival in gastric cancer from two phase III studies of second-line ramucirumab (REGARD and RAINBOW) using pooled patient data. J Gastric Cancer. 2017;17:132-44.

28. Jung M, Ryu MH, Oh DY, Kang M, Zang DY, Hwang IG, et al. Efficacy and tolerability of ramucirumab monotherapy or in combination with paclitaxel in gastric cancer patients from the expanded access program cohort by the Korean Cancer study group (KCSG). Gastric Cancer. 2018;21:819-30.

29. Fuchs CS, Tabernero J, Tomášek J, Chau I, Melichar B, Safran H, et al. Biomarker analyses in REGARD gastric/GEJ carcinoma patients treated with VEGFR2-targeted antibody ramucirumab. Br J Cancer. 2016;115:974-82.

30. Cho IR, Park JC, Park CH, Jo JH, Lee HJ, Kim S, et al. Pre-treatment neutrophil to lymphocyte ratio as a prognostic marker to predict chemotherapeutic response and survival outcomes in metastatic advanced gastric cancer. Gastric Cancer. 2014;17:703-10.

31. Hashemi-Bahremani M, Mortazavi N, Novin K, Ameri A, Razzaghi Z. Blood neutrophil-to-lymphocyte ratio as a predictor of response to chemotherapy in head-and-neck cancers. J Head Neck Physicians Surg. 2019;7:20-5.

32. Adamowicz K, Romanowska A, Zaucha RE. Prognostic value of the neutrophil-to-lymphocyte ratio (NLR) in advanced non-small cell lung cancer. Ann Oncol. 2018;29:viii493-547.

33. Ogata $T$, Satake $H$, Ogata $M$, Hatachi $Y$, Inoue $K$, Hamada $M$, et al. Neutrophil-to-lymphocyte ratio as a predictive or prognostic factor for gastric cancer treated with nivolumab: a multicenter retrospective study. Oncotarget. 2018;9:34520-7.

34. Bagley SJ, Kothari S, Aggarwal C, Bauml JM, Alley EW, Evans TL, et al. Pretreatment neutrophil-to-lymphocyte ratio as a marker of outcomes in nivolumab-treated patients with advanced non-small-cell lung cancer. Lung Cancer. 2017:106:1-7.

35. Tada Y, Togashi Y, Kotani D, Kuwata T, Sato E, Kawazoe A, et al. Targeting VEGFR2 with Ramucirumab strongly impacts effector/ activated regulatory T cells and CD8+ T cells in the tumor microenvironment. J Immunother Cancer. 2018;6:106.

\section{Publisher's Note}

Springer Nature remains neutral with regard to jurisdictional claims in published maps and institutional affiliations.

Ready to submit your research? Choose BMC and benefit from:

- fast, convenient online submission

- thorough peer review by experienced researchers in your field

- rapid publication on acceptance

- support for research data, including large and complex data types

- gold Open Access which fosters wider collaboration and increased citations

- maximum visibility for your research: over $100 \mathrm{M}$ website views per year

At BMC, research is always in progress.

Learn more biomedcentral.com/submissions 